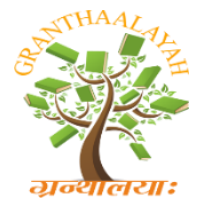

INTERNATIONAL JOURNAL OF RESEARCH GRANTHAALAYAH A knowledge Repository

Science

\title{
DENITRIFICATION KINETICS OF PSEUDOMONAS STUTZERI AZ101
}

\author{
Ahmad Idi *1 \\ ${ }^{* 1}$ Department of Biological Sciences, Adamawa State University, Mubi, Nigeria
}

\begin{abstract}
Nitrogen removal from environment is significant due to its effect on health and the whole ecosystems. Hence a highly nitrogen tolerant aerobic denitrifier, Pseudomonas stutzeri AZ101 was isolated from aquaculture wastewater and characterized using $16 \mathrm{~S}$ rRNA analysis. The ability of the isolate to carry out simultaneously nitrification and denitrification (SND) was investigated. Different initial concentrations of nitrate and ammonium were used to determine the rate of SND. The denitrification data fitted well with the second order reaction kinetics with correlation coefficient between 0.923-0.9588. The nitrification data does not fit to both first and second order reaction kinetic but progressive shifts in the logarithm phase of the growth were observed at different initial concentrations. The kinetics data provide a significant insight to nitrogen removal from the wastewater.
\end{abstract}

Keywords: Denitrification; Nitrification; Pseudomonas Stutzeri AZ101; Kinetics Reaction; Second Order Reaction.

Cite This Article: Ahmad Idi. (2019). "DENITRIFICATION KINETICS OF PSEUDOMONAS STUTZERI AZ101." International Journal of Research - Granthaalayah, 7(7), 247-255. https://doi.org/10.29121/granthaalayah.v7.i7.2019.758.

\section{Introduction}

Industrial and agricultural developments result in the release of large quantities of toxic nitrogenous compounds into the environment. For instance, livestock farming and fertilizer application alone contribute to about $90 \%$ of total ammonium released into the soil and water bodies [1]. These compounds have been shown to have negative impact on the surrounding environment. Ammonium can cause cancer via its conversion into toxic by-products. In fish, its toxicity manifest when the concentration exceed $0.04 \mathrm{mg} / \mathrm{L} \mathrm{[2].}$

Bio-removal of ammonium by conventional method consists of nitrification by autotrophs and denitrification by heterotrophs under aerobic and anaerobic condition respectively [3]. Since this method is operated under different growth conditions, two separate systems are required. The complexity in separating these systems and slow nitrification rate are amongst the drawback of the system. The process is also performed under low ammonium concentration and is characterized by slow nitrification rate due to low bacterial activity [4]. These restrict its potential application in 
industrial and agricultural wastewaters treatment plants, which consist of high amount of ammonium.

To overcome such challenges, a method that combines the two processes together is giving more preference. In such system commonly refer to as simultaneous nitrification and denitrification (SND), bacteria do not only carry out heterotrophic nitrification but also denitrify the nitrification products under aerobic condition. The process is characterized by high removal rate, minimum reaction time, small reactor volume and less energy input due to lack of circulation of liquid between the aerobic and anaerobic systems [5]. Many different bacteria are capable of performing SND, most of which includes Agrobacterium sp LAD9 [3], Bacillus subtilis A1[6], Acinetobacter sp. HA2 [7], Klebsiella pneumonia CF-S9 [8].

Even though many different bacteria are capable of SND, the nitrifying and denitrifying ability varies from specie to specie. Some species possess low tolerance level to nitrogen, as such not suitable for high strength wastewater. Furthermore, the rate of nitrification and denitrification is essential in selecting a suitable candidate for high strength wastewater. This study therefore aimed at isolating aerobic denitrifier and determining the kinetic coefficients for the removal of toxic nitrogenous compounds.

\section{Materials and Methods}

\section{Isolation of Bacteria}

The bacterium was isolated by enrichment method using Basal medium. The Basal medium contained $0.33 \mathrm{~g}$ of $\mathrm{KH}_{2} \mathrm{PO}_{4}, \mathrm{MgSO}_{4} .7 \mathrm{H}_{2} \mathrm{O}$, and $\mathrm{NaCl}, 0.02 \mathrm{~g}$ of yeast extract, 0.5 of $\mathrm{NH}_{4} \mathrm{Cl}, 0.05$ $\mathrm{g}$ of $\mathrm{CaCl}_{2} .2 \mathrm{H}_{2} \mathrm{O}$, and $1.0 \mathrm{~g}$ of disodium succinate per litre. The medium also contained $0.5 \mathrm{ml}$ of $0.02 \% \mathrm{FeSO}_{4} .7 \mathrm{H}_{2} \mathrm{O}$ and $1 \mathrm{ml}$ of sterile trace element. The trace element contained $10 \mathrm{mg}$ of $\mathrm{ZnSO}_{4} .7 \mathrm{H}_{2} \mathrm{O}, 3 \mathrm{mg}$ of $\mathrm{MnCl}_{2} \cdot 4 \mathrm{H}_{2} \mathrm{O}, 30 \mathrm{mg}$ of $\mathrm{H}_{3} \mathrm{BO}_{3}, 20 \mathrm{mg}$ of $\mathrm{CoCl}_{2} \cdot 6 \mathrm{H}_{2} \mathrm{O}, 1 \mathrm{~m}$ of $\mathrm{CuCl}_{2} \cdot 2 \mathrm{H}_{2} \mathrm{O}$, $2 \mathrm{mg}$ of $\mathrm{NiCl}_{2} \cdot 6 \mathrm{H}_{2} \mathrm{O}, 3 \mathrm{mg}$ of $\mathrm{Na}_{2} \mathrm{MoO}_{4}, 1$ liter of distilled $\mathrm{H}_{2} \mathrm{O}$ and between $\mathrm{pH} 3-4$. For preparation of solid medium, $15 \mathrm{~g}$ of agar was added to the above mentioned medium. The sample for isolation of bacteria was obtained from an aquaculture wastewater at iSHARP SDN BHD Terranganu Malaysia. About $5 \mathrm{ml}$ of the wastewater was transferred into the Basal medium and incubated at $37{ }^{\circ} \mathrm{C}$ with shaking speed of $150 \mathrm{rpm}$ for $48 \mathrm{hrs}$. Then $1 \mathrm{ml}$ of the enrichment culture was transferred into a fresh enrichment culture and incubated as described above. The bacteria were obtained by serial dilution and spread plate technique. Purified single colonies were obtained by repeated streaking.

\section{Molecular Characterization of the Isolate}

Promega wizard genomic DNA purification kit was used for the genomic DNA extraction and purification following the manufacturer's protocol. The PCR amplification of the 16S rRNA gene was amplified with universal primers 14-F 5"AGAGTTTGATCCTGGCTCAG3" and 1492-R 5"GGTTACCTTGTTACGACTT3". PCR condition was set at $3 \mathrm{~min}$ at $95^{\circ} \mathrm{C}$ for initial denaturalization, 30 cycles of $1 \mathrm{~min}$ at $95^{\circ} \mathrm{C}$ for denaturalization, $30 \mathrm{sec}$ at $52^{\circ} \mathrm{C}$ for annealing, 1 $\min$ at $72^{\circ} \mathrm{C}$ for extension and $10 \mathrm{~min}$ at $72^{\circ} \mathrm{C}$ for final extension. The concentration and purity of the extracted genomic DNA was determined using agarose gel electrophoresis and Nano drop. Ethidium bromide was used as a stain for the agarose gel electrophoresis. The PCR product was sent to $1^{\text {st }}$ Base Company in Selangor, Malaysia for sequencing. The sequence obtained from the 
Company was assembled using Bioedit software version V7.2.5 and online BLAST program was used to compare with other sequence in the gene bank at http://blast.ncbi.nlm.nih.gov/Blast.cgi. The phylogenic tree was constructed using neighbor joining method with MEGA 4 software.

\section{Experimental Set up}

The same Basal medium described in the isolation of bacteria was used for the kinetics study. However different initial concentrations of 72, 108, 180, 212, and $360 \mathrm{mg} / \mathrm{L}$ of $\mathrm{NaNO}_{3}$ were used for dentrification process while 95, 212, 320 and $420 \mathrm{mg} / \mathrm{L}$ of $\mathrm{NH}_{4} \mathrm{Cl}$ were used for the nitrification process. The kinetic experiment was conducted at $37^{\circ} \mathrm{C}$ with shaking speed of $150 \mathrm{rpm}$. For denitrification, six flasks were used and sample were withdrawn at the end of every 24 hour to determine the OD and later centrifuged to measure the amount of nitrate. For nitrification, sample was withdrawn every 6 hour for analysis as reported earlier [9].

\section{Kinetics Derivation}

The first order and second order chemical reactions kinetics where used to illustrate the rate of denitrification using Pseudomonas stutzeri AZ101 as described by [10]. The first order kinetic is given as $\frac{d[\mathrm{~N}]}{d t}=K C_{N}$ while the second order kinetic is given as: $\frac{d\left[\mathrm{NO}_{3}^{+}\right.}{d t}=C N_{0} \times K=C N \times K \rightarrow$ (1)

and $\frac{d X}{d t}=C X_{0} \times K=-C X \times K \rightarrow(2)$ Combining equation (1) and (2), the second order kinetics becomes

$\frac{d N}{d t}=K^{1} C N \times C X_{0}=-K^{1} C N_{0} \times C X \rightarrow(3)$. By separating the variables, integrating and linearization, it becomes: $\ln \left[\frac{C N_{0}}{C N} \times \frac{C X_{0}}{C X}\right]=K^{1} t\left(C X-C N_{0}\right)$. The first order becomes: $\ln C_{N}=$ $K t+\ln C N_{0}$.

Where $\mathrm{CX}=$ Biomass concentration and $\mathrm{CN}=$ Nitrate concentration, $\mathrm{CX}_{0}$ and $\mathrm{CN}_{0}$ are initial concentrations of $\mathrm{CX}$ and $\mathrm{CN}$ and are defined as follows: $C N_{0}-N=C N$ and $C X_{0}=C X-N$.

\section{Analytical Method}

The optical density $\left(\mathrm{OD}_{600}\right)$ was spectrophotometrically measured using $\mathrm{HACH}$ spectrophotometer DR $6000^{\mathrm{TM}}$. Ammonium was measured using Nessler method, nitrate by Cadmium reduction method and Nitrite by Ferrous sulfate method as described using APHA technique.[11]

\section{Results and Discussion}

\subsection{Isolation and Characterization of Bacteria}

Twelve different isolates were obtained. The isolates were purified by repeated streaking on fresh agar and later screened for denitrification by growing each of the isolate on denitrifying medium. The isolate designated as "AZ" showed higher denitrification ability compared to the other and therefore selected for the study. The colonies of AZ were yellow in coloration, short rod shaped and gram negative. Sequencing of the PCR products of the 16S rRNA gene produced 1433 base pairs which showed $99 \%$ similarity to Pseudomonas stutzeri W12 when compared with other sequences in GenBank by BLAST. The sequence was later deposited to NCBI with accession 
number KP065811.1. Phylogenic tree (Fig.1) was constructed to show the relationship between P.stutzeri AZ101 and other denitrifying bacteria.

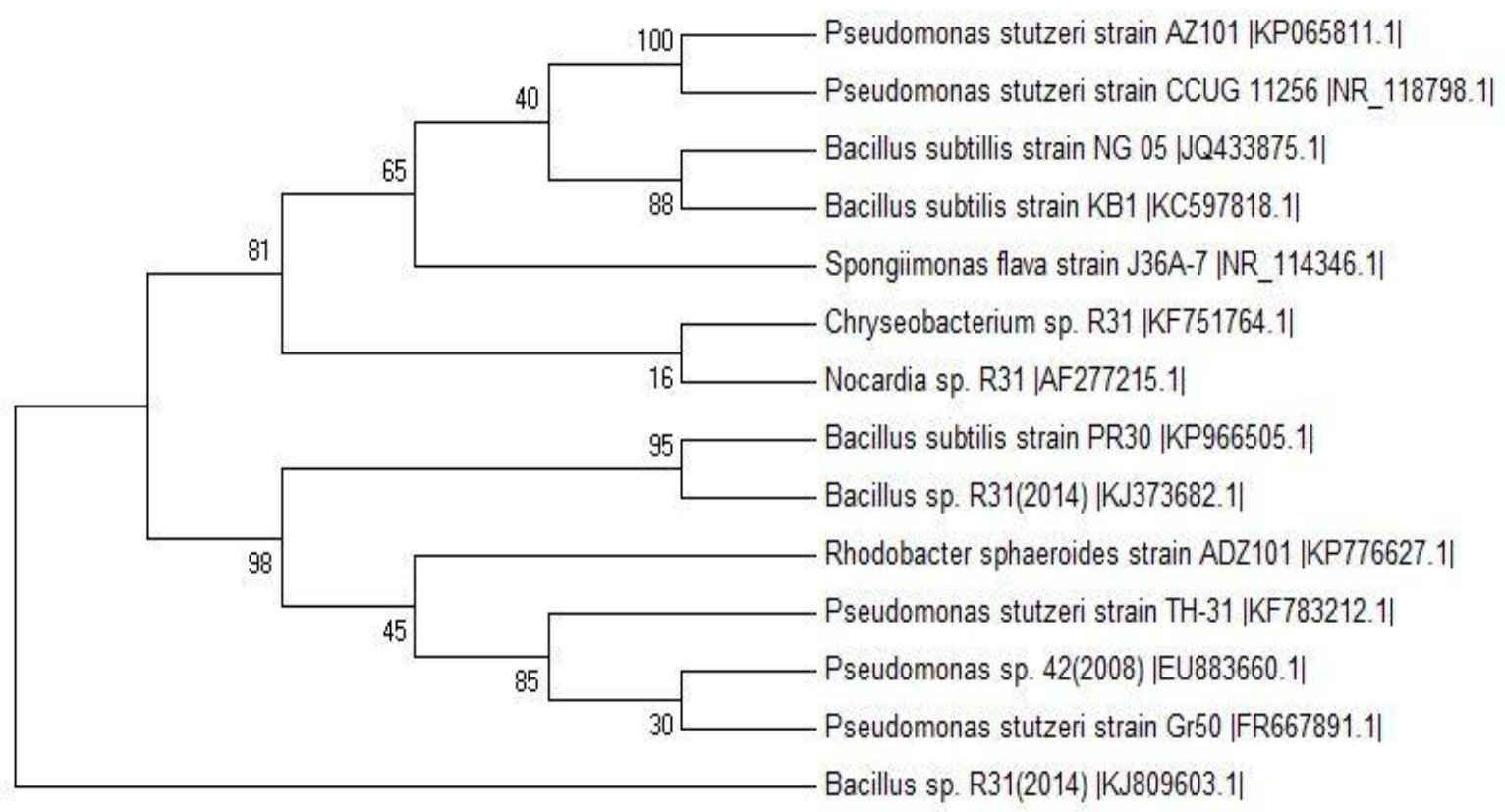

Figure 1: phylogenetic tree based on 16s rRNA showing the relationship between Pseudomonas stutzeri AZ101 and other bacteria

\subsection{Denitrification kinetics}

The first and second order reactions kinetics were used to determine the influence of different initial concentrations on the rate of nitrate removal using Pseudomonas stutzeri AZ101. The reaction kinetics described quantitatively the rate coefficient of the removal process. From this study, the first order kinetics has minimum application for nitrate removal, so does not fit well with the model having regression coefficient between 0.002-0.587. However, the second order kinetics model is well fitted with regression coefficient between $0.9023-0.9588$ as seen in Fig. 2 This result is in agreement with the previous study of [10] for cadmium removal. The $\mathrm{R}^{2}$ value was found to be closer to one, indicating a well fitted model. Regression coefficient value not up to one in this study is likely due to the formation of $\mathrm{N}_{2} \mathrm{O}$ as evident by the little formation of bubble during the growth and the postulation of [12] that small amount of $\mathrm{N}_{2} \mathrm{O}$ is form during partial dissimilation of nitrate to ammonium. 

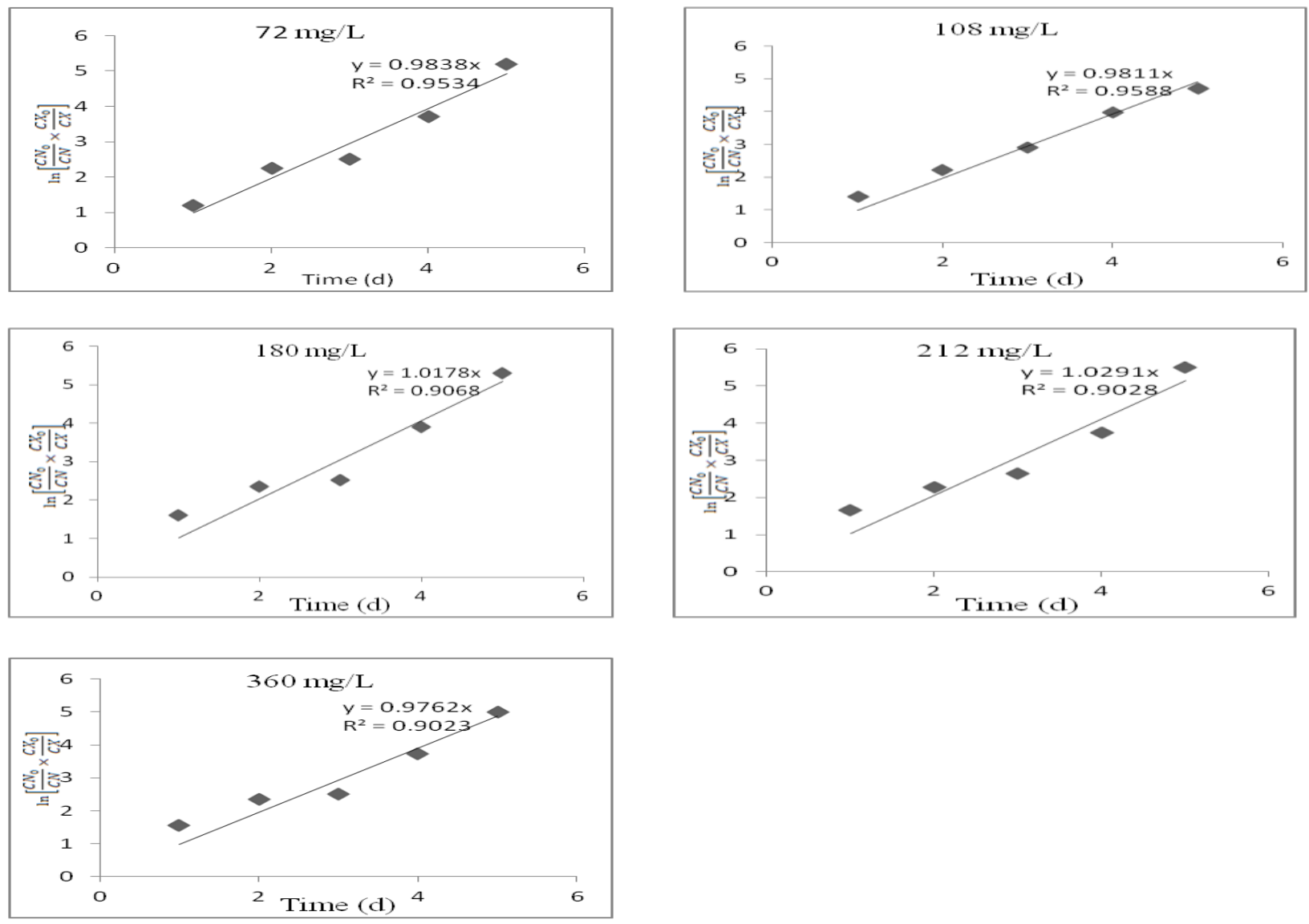

Figure 2: second order kinetic models of different initial concentrations of nitrate

Comparing the percentage rate value of $k$ for each day of different initial concentrations revealed that the nitrate removal rate is similar in all the days of the experiment at a specific percentage rate of $80 \%$. This indicates the proportionality of biomass production and nitrate removal in all the days of the experiment. However both nitrate removal and biomass production will reach it maximum and begin to decline due some inhibition mechanisms.

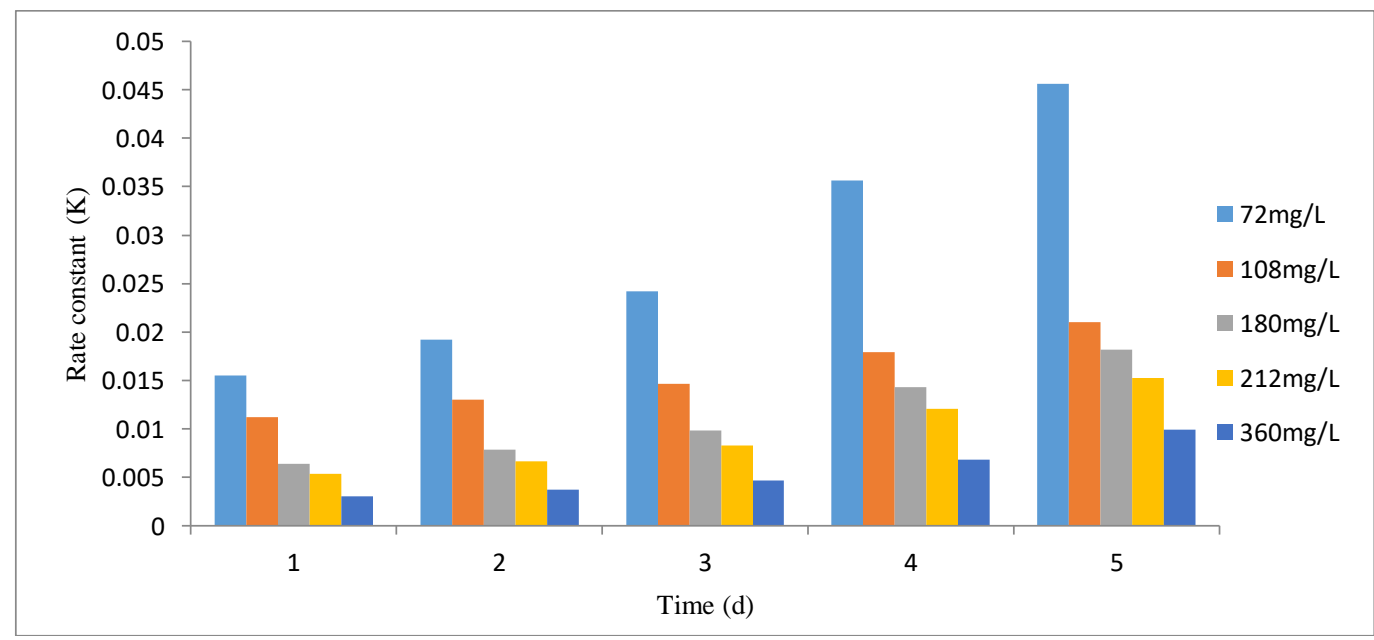

Figure 3: Rate constant for each day of the experiment 
The rate of removal was found to be higher in lower concentrations and progress steady as the concentration increased as shown in Fig. 3. This trend was also observed when the mean value of $k$ for each concentration was compared. At initial concentration of $72 \mathrm{mg} / \mathrm{L}$, the mean of $k$ was 0.025651 while 0.005155 was obtained at initial concentration of $360 \mathrm{mg} / \mathrm{L}$. This showed about $80 \%$ decrease in the removal rate before it came to halt when the concentration was increased above $360 \mathrm{mg} / \mathrm{L}$. Fig. 4 gives the average mean constant of $k$ for each concentration.

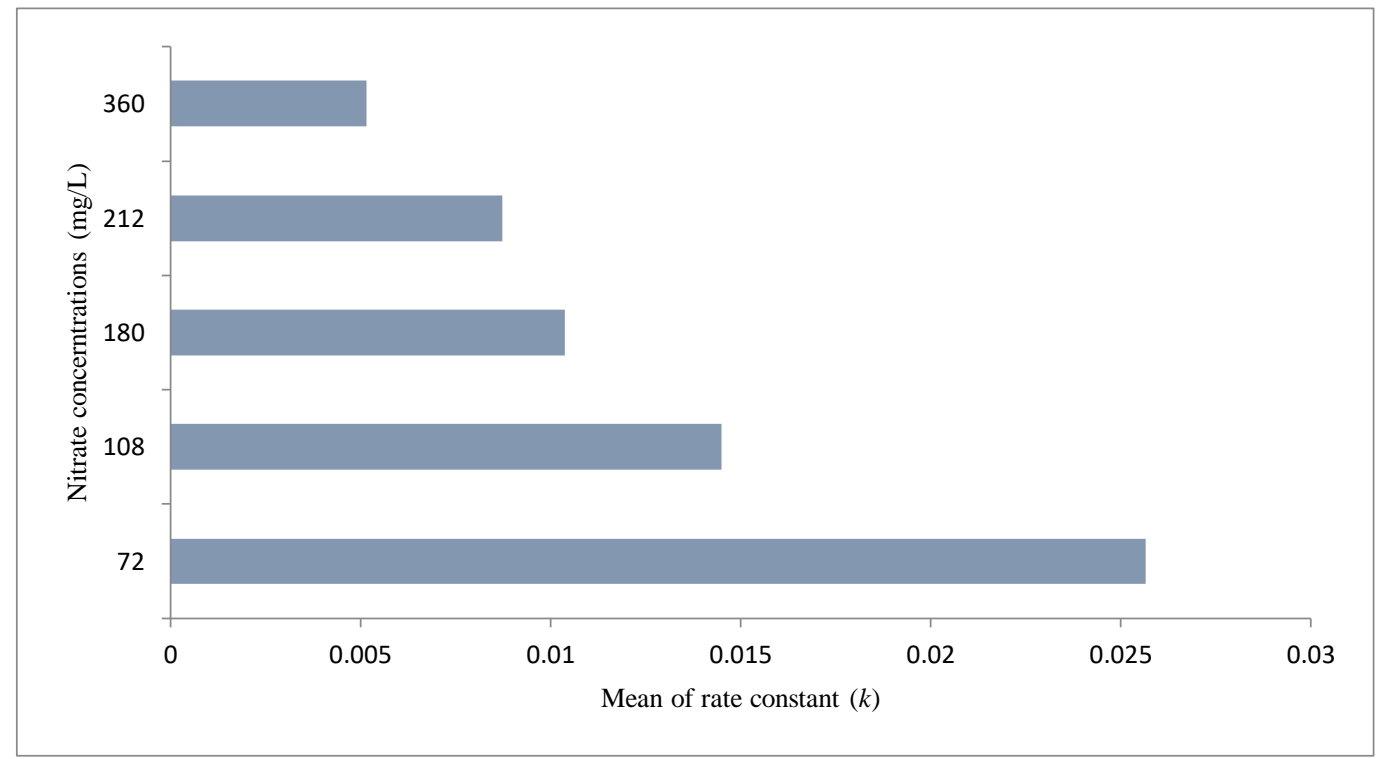

Figure 4: mean constant of $k$ for each concentration

\subsection{Nitrification Pattern}

The potential of ammonium removal using Pseudomonas stutzeri AZ101 was also investigated at different initial concentrations. Even though ammonium removal is related to growth, it does not fit well for both first and second order kinetics. This may be attributed to the nature of bacteria and its growth condition requirements [13] who reported ammonium uptake using first order kinetics suggested that the characteristic of bacterial specie and its growth condition can play an interacting role for its growth rate and ammonium uptake.

Different growth patterns were observed at different initial ammonium concentrations. At initial concentration of $95 \mathrm{mg} / \mathrm{L}$, no lag phase was observed. Within 6 hours the growth reached its stationary phase and began to slow down. At $215 \mathrm{mg} / \mathrm{L}$, the growth reached it stationary phase at approximately 12 hours before slow growth was observed. Similar pattern of shift in the stationary phase was observed at initial concentration of $320 \mathrm{mg} / \mathrm{L}$ and $420 \mathrm{mg} / \mathrm{L}$. The stationary phases of these concentrations moved from 18 to 24 hours respectively. Since all the experimental conditions are the same, except the initial concentration, it is suggested that different initial concentration may be responsible for the shift of the stationary phase of the growth curve which followed the same pattern. 


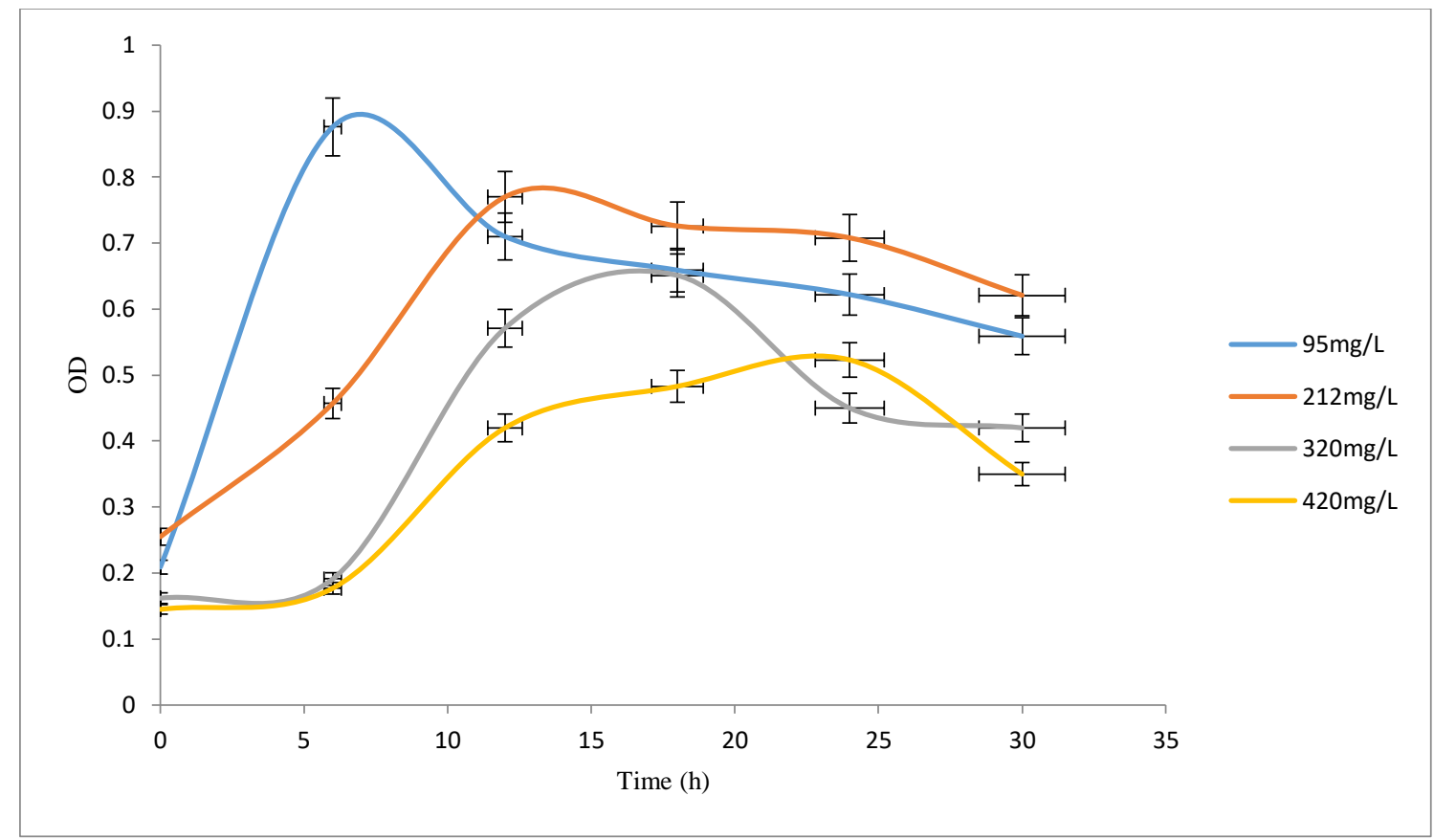

Figure 5: Growth pattern of $P$ stutzeri AZ101 at different initial concentrations

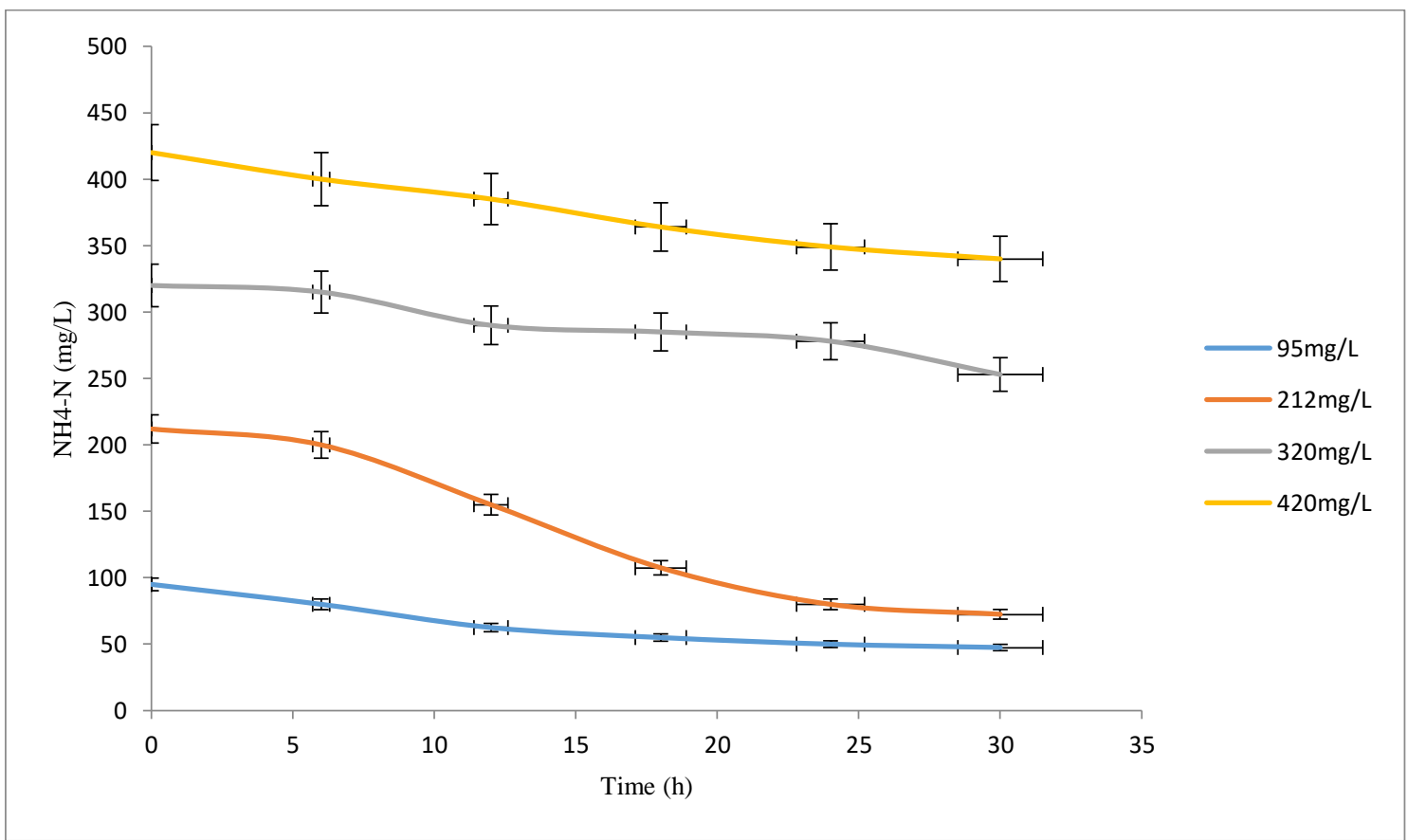

Figure 6: Ammonium removal of different initial concentrations

The growth pattern and ammonium removal are illustrated in Fig. 5 and 6 respectively. At lower initial concentration of $95 \mathrm{mg} / \mathrm{L}, 50 \%$ of ammonium was removed. The percentage increased to 60 at $212 \mathrm{mg} / \mathrm{L}$. As the concentration increased further to $320 \mathrm{mg} / \mathrm{L}$, the percentage of removal began to decline to 12 and 19 when $420 \mathrm{mg} / \mathrm{L}$ was used. This is due to the fact that ammonium assimilation has being linked to its concentration in the growth medium [14]. High concentrations result in higher uptake which is necessitated by the synthesis of many protein carriers. At low 
concentration, its uptake has been shown to be an active process using specific carrier [15]. This specific carrier is synthesized at low concentrations and repressed at high concentrations. From this study, the optimum synthesis of this specific carrier was at the concentrations of $212 \mathrm{mg} / \mathrm{L}$ where $60 \%$ of ammonium was removed. Followed by $95 \mathrm{mg} / \mathrm{L}$ where $50 \%$ was removed. And it repression began at the concentrations of $320 \mathrm{mg} / \mathrm{L}$ and $420 \mathrm{mg} / \mathrm{L}$ where 12 and 19\% were removed respectively.

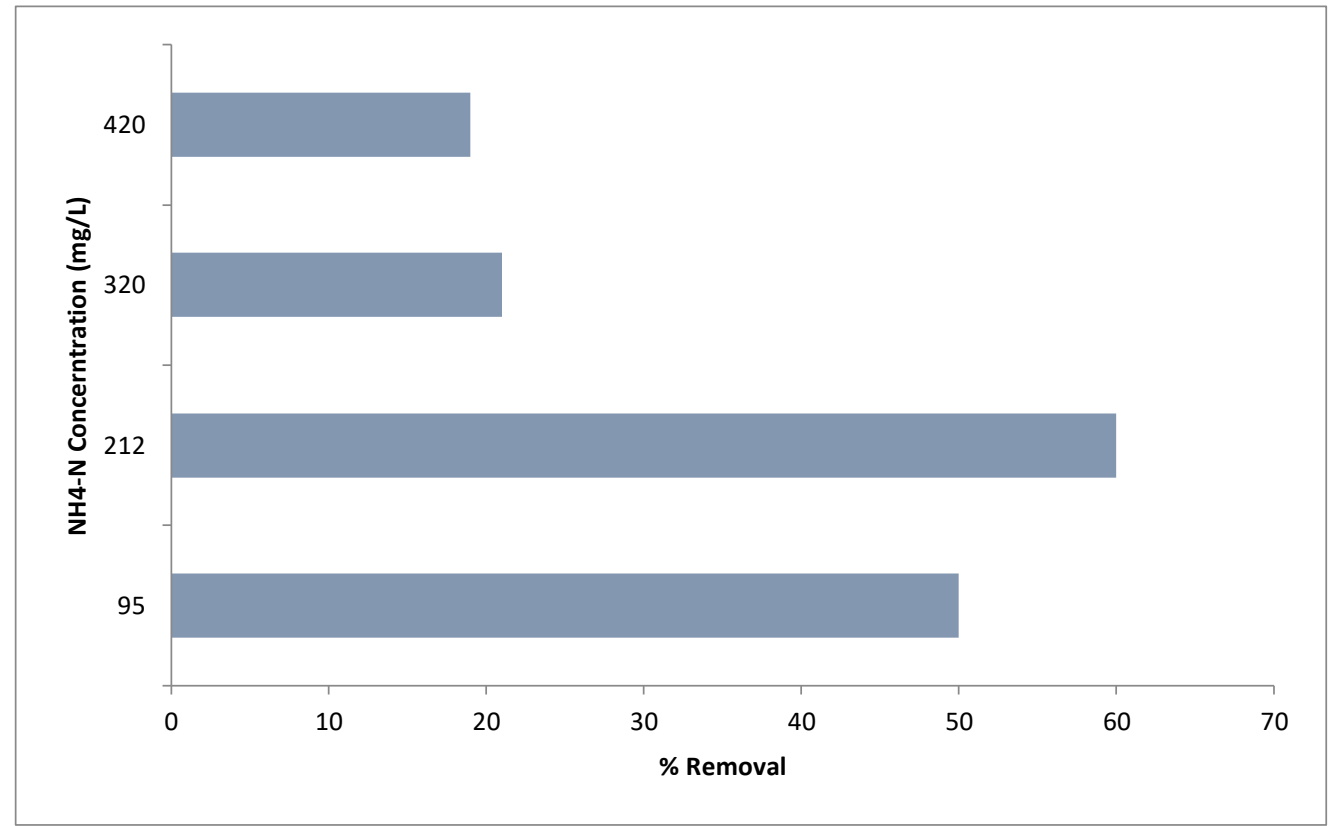

Figure 7: percentage of ammonium removal at different initial concentration

\section{Conclusion}

Pseudomonas stutzeri AZ101 can tolerate high amount of both nitrate and ammonium hence possess high possibility for industrial application in simultaneous nitrification and denitrification processes. Denitrification data fitted well with second order reaction kinetics while nitrification data does not fit well for both first and second order kinetics. This study however provides fundamental information about the possibility of using this strain in biological wastewater treatment further study is therefore recommended to obtain the optimum conditions of the removal.

\section{References}

[1] Phillips, J., Control and pollution prevention options for ammonium emissions. 1995, VIGYAN, Inc., Vienna, VA (United States).

[2] Zhang, S., et al., Ammonium removal at low temperature by a newly isolated heterotrophic nitrifying and aerobic denitrifying bacterium Pseudomonas fluorescens wsw-1001. Environmental technology, 2015: p. 1-7.

[3] Qian, C. and N. Jinren, Ammonium removal by Agrobacterium sp. LAD9 capable of heterotrophic nitrification-aerobic denitrification. Journal of bioscience and bioengineering, 2012. 113(5): p. 619623.

[4] Young-Ho, A., Sustainable nitrogen elimination biotechnologies: A review. Process Biochemistry, 2006. 41. 
[5] Pradyut, K., et al., Simultaneous Heterotrophic Nitrification and Aerobic Denitrification by Chryseobacterium sp. R31 Isolated from Abattoir Wastewater. BioMed Research International, 2014.

[6] Xin-Ping, Y., et al., Isolation and nitrogen removal characteristics of an aerobic heterotrophic nitrifying-denitrifying bacterium, Bacillus subtilis A1. Bioresource technology, 2011. 102(2): p. 854-862.

[7] Shuo, Y., et al., Heterotrophic nitrification and aerobic denitrification at low temperature by a newly isolated bacterium, Acinetobacter sp. HA2. Bioresource technology, 2013. 139: p. 80-86.

[8] Soumesh Kumar, P., et al., Characterisation of heterotrophic nitrifying and aerobic denitrifying Klebsiella pneumoniae CF-S9 strain for bioremediation of wastewater. International Biodeterioration \& Biodegradation, 2013. 78: p. 6773.

[9] Idi, A., et al., Biokinetics of nitrogen removal at high concentrations by Rhodobacter sphaeroides ADZ101. International Biodeterioration \& Biodegradation, 2015. 105: p. 245-251.

[10] Bai, H.-J., et al., Bioremediation of cadmium by growing Rhodobacter sphaeroides: kinetic characteristic and mechanism studies. Bioresource Technology, 2008. 99(16): p. 7716-7722.

[11] E.W. Rice, R.B.B., A.D. Eaton, L.S. Clesceri, Standard Methods for the Examination of Water and Wastewater. . American Public Health Association, American Water Works, Association, Water Environment Federation., 2012.

[12] Knowles, R., Denitrification. Microbiological reviews, 1982. 46(1): p. 43.

[13] Annuar, M., et al., Ammonium uptake and growth kinetics of Pseudomonas putida PGA1. AsiaPacific Journal of Molecular Biology and Biotechnology, 2006. 14(1): p. 1-10.

[14] Merrick, M. and R. Edwards, Nitrogen control in bacteria. Microbiological Reviews, 1995. 59(4): p. 604-622.

[15] Kleiner, D., Bacterial ammonium transport. FEMS Microbiology Letters, 1985. 32(2): p. 87-100.

\footnotetext{
*Corresponding author.

E-mail address: ahmadidy2010@ gmail.com
} 